\title{
Microstructures in Medicinal Mushroom Cultures
}

\author{
Asya S. Buchalo, ${ }^{1}$ Maryna Ya. Didukb, ${ }^{1}$ Oksana B. Mykchaylova, ${ }^{1}$ \\ E Vita M. Lynovitska ${ }^{2}$
}

${ }^{1}$ M.G. Kholodny Institute of Botany, National Academy of Sciences of the Ukraine, 2 Tereshchenkivska St., Kiev 01001, Ukraine; ${ }^{2}$ NTUU “KPI”, Faculty of Biotechnology and Biotechnique, 37 Peremogy Ave., Kiev, Ukraine

The correct identification of the taxonomic position of mushroom cultures due to their biotechnological application is a task of paramount importance. A dolipore septae and clamp connections are basic characteristics of Basidiomycetes cultures. A detailed study of clamp connections, anamorphs, and vegetative mycelium structures allows for more accurate morphological characterization of taxa introduced in pure culture.

Vegetative mycelium microstructures of more than 150 macromycetes species (Basidiomycota and Ascomycota) were studied using scanning electron microscopy (SEM). New data were obtained on the fine microstructures in cultures of medicinal mushroom species of the genera Pleurotus, Ganoderma, Trametes, Agaricus, Auricularia, Oudemansiella, Coprinus, Marasmius, Morchella, and species Lentinus edodes (Berk.) Singer, Hericium erinaceus (Bull.) Pers., Grifola frondosa (Dicks.:Fr.) S.F.Gray, Hypsizygus marmoreus (Peck) H.E. Bigelow, Schizophyllum commune Fr.:Fr., Piptoporus betulinus (Bull.: Fr.) P.Karst., Omphalotus olearius (DC.:Fr.) Singer, Laetiporus sulphureus (Bull.:Fr.) Murrill, Polyporus squamosus (Huds.) Fr., etc.

The presence and dislocation of clamp connections on hyphae are essential taxonomic characteristics for some species. Some species have clamps of an original form, namely Oudemansiella mucidum (Schrad.) Höhn., Auricularia auricula-judae (Fr.) Quél., and Lentinus tigrinus (Bull.:Fr.) Fr.; whereas Piptoporus betulinus (Bull.:Fr.) P. Karst., Pleurotus ostreatus (Jacq.:Fr.) P.Kumm., and Lyophyllum decastes (Fr.) Singer are characterized with clamp connections of various forms and sizes. Single clamps, whorls of clamps, coupled clamps, and sprouted clamps were observed in cultures of these mushrooms. Clamps are constant in cultures belonging to species of Pleurotus, Coprinus, Oudemansiella, Panus, Lentinus, and Pholiota, but very rarely occurred in vegetative mycelium of Agaricus spp. (A. subperonatus (J.E. Lange) Singer, $A$. arvensis Schaeff., $A$. bernardii Quél., $A$. comtulus Berk. et Broome, $A$. campestris L.:Fr., $A$. maskae Pilát, $A$. bernardiiformis Bohus, $A$. comtulus, and $A$. brasiliensis $\mathrm{S}$. Wasser et al.).

Different structures of asexual reproduction (anamorphs) may serve as taxonomic criterion at the species level. Arthroconidia have been found in the mycelial cultures of Oudemansiella spp. Lepista nuda (Bull.:Fr.) Cooke, Omphalotus olearius, Agaricus abruptibulbus Peck, $A$. bernardiiformis, $A$. fissuratus (F.H. Møller) F.H. Møller, A. macrocarpus (F.H. Møller) F.H. Møller, A. maskae, A. squamuliferus (F.H. Møller) Pilát, A. cupreobrunneus (Jul. Schäff. et Steer) Pilát, $A$. silvaticus Schaeff., $A$. arvensis, Hypsizygus marmoreus, Lyophyllum ulmarium (Bull.:Fr.) Kühner, Paxillus acheruntius (Humb.) J. Schröt., Polyporus squamosus (Huds.: Fr.) Fr., etc. Formation of coremia is known only for Pleurotus abalonus Y.H. Han, K.M. Chen et S. Cheng and P. cystidiosus O.K. Mill. Single globose conidia, or excretory cells, on simple conidiophores, resembling a sterigmata of the basidium, are formed 
on hyphae in cultures of Pleurotus spp. and Schizophyllum commune. Chlamydospores in dicaryotic Hericium erinaceus cultures, dichohyphidia, and intercalar chlamydospores of Grifola frondosa are of taxonomic significance. An anamorphic state of oidium and Costantinella type is characteristic for Morchellaceae. Chlamydospores were discovered in cultures of Agaricus bisporus (J.E. Lange) Imbach, $A$. arvensis, Leucocoprinus birnbaumii (Corda) Singer, Macrolepiota subsquarrosa (Locq.) Bon, Handkea excipuliformis (Scop.) Kreisel, Langermmania gigantea (Batsch.) Rotsk., Boletus edulis Bull.:Fr., B. quletii Schulzer, Suillus bovinus (Pers.) Kuntze, Marasmius androsaceus (L.:Fr.) Fr., Hypsizygus marmoreus, Coriolus zonatus (Nees) Quél., Auricularia auricula-judae, A. polytricha (Mont.) Sacc., etc.

For Coprinus cinereus (Schaeff.) S.F.Gray, Crinipellis sherczenkovi Buchalo, Agaricus gennadii (Chatin et Boud.) P.D.Orton, and Leucocoprinus bresadolae (Schulzer) S.Wasser cultures sclerotia are known. Strand-like mycelial cords were found in cultures of Agaricus arvensis, A. bisporus (J.E. Lange) Imbach, $A$. bitorquis (Quél.) Sacc., $A$. campestris, A. subfloccosus (J.E. Lange) Pilát, $A$. vaporarius
Krombh., A. brasiliensis, Macrolepiota procera (Scop.) Singer, $M$. excoriata (Schaeff.) M.M. Moser, $M$. mastoidea (Fr.) Singer, Omphalotus olearius, Russula ionochlora Romagn., Phallus impudicus L., Lycoperdon pyriforme Schaeff., Scleroderma citrinum Pers., and Tulostoma berteroanum Speg.

Hyphae ornamentation observed in Lyophyllum spp. cultures may serve as taxonomic characters. Warty ornamentations were detected in Oudemansiella brunneomarginata Lj.N. Vassiljeva and O. mucida on the loop forming hyphae. Lacunose structured hyphae are described in some species of Morchellaceae. Formation of calcium oxalate crystals was observed in all investigated species of Agaricus. Polygonal, hair-like crystals and crystals of other shapes were observed in Hypsizygus marmoreus, Hericium erinaceus, Lentinus edodes, Armillariella mellea (Vahl) P. Karst., Pholiota jahnii Tjall.Beuk. et Bas, Clitocybe odora (Bull.:Fr.) P. Kumm., Kuebneromyces mutabilis (Schaeff.) Singer et A.H. Sm., Peniophora gigantea (Fr.) Massee, Omphalotus olearius, Coprinus comatus (O.F. Müll.) S.F.Gray, Agaricus fissuratus, A. subfloccosus, and Montagnea arenaria (DC.) Zeller. 